Members of the South Bedfordshire Practitioners' Group are Gina Johnson, Ian Hill-Smith, Richard Brown, Chris Ellis, Zyg Evershed, Pravin Goutam, Paul Hassan, Andrew Long, Jane Perkins, Del Roberts, Cathy Sykes, Kathy Swan, Sara Warriner, and Martin Waldron.

We thank Mr Ron Driver of Luton College for statistical advice, and our practice staff for their patience.
1 Johnson G, Roberts D, Brown R, Cox E, Evershed Z, Goutam P, et al. Infertile or childless by choice? A multipractice survey of women aged 35 and $50 . B M$ 1987;294:804-6.

2 Greenhall E, Vessey $M$. The prevalence of subfertility: a review of the curren confusion and a report of two new studies. Fertil Steril 1990;54:978-83.

3 Templeton A, Fraser C, Thompson B. The epidemiology of infertility in Aberdeen. BMf 1990;301:148-52.

4 Jones C. Fertility of the over thirties. Population Trends 67:10-6. London: HMSO, 1992.

(Accepted 8 fuly 1993)

\section{Value of radiological follow up of childhood pneumonia}

\section{N A Gibson, A S Hollman, J Y Paton}

Departments of Child Health and Radiology, Royal Hospital for Sick Children, Glasgow G3 8SJ N A Gibson, senior registrar, respiratory paediatrics A S Hollman, consultant paediatric radiologist J Y Paton, senior lecturer, respiratory paediatrics

Correspondence to: Dr Paton

BM于 1993;307:1117

Children with community acquired pneumonia are recommended to have follow up chest radiography three to four weeks after discharge from hospital to confirm radiological resolution. ${ }^{1} \mathrm{~A}$ recent reappraisal of the lifetime risk of diagnostic $x$ ray exposure in children stressed the need to minimise it. ${ }^{2}$ We were concerned that follow up films were unnecessary and have examined their usefulness.

\section{Subjects, methods, and results}

The chest radiographs of children with opacification consistent with pneumonic consolidation were identified by radiologists. Children with asthmatic attacks, compromised immunity, or pre-existing disease were excluded. Pneumonia was diagnosed based on a history of acute respiratory symptoms, fever, clinical findings, and suitable radiographic changes.

Inpatient management and radiological investigation of the children were left to the responsible clinician who had the routine radiological opinion available. For the study all films were reviewed by ASH. An appointment was offered three to four weeks after discharge from hospital for clinical and radiological review. Defaulters were sent one further appointment.

Seventy seven consecutive children (median age 4 years, range 2 months- 12 years) fulfilled the study criteria over two years. Sixty nine had typical clinical presentations of pneumonia, three had febrile convulsions, four abdominal pain, and one shoulder pain Only nine children had microbiological diagnoses, and these were unrelated to specific clinical or radiological features.

A total of 111 chest radiographs were taken in the 77 children (one to six films per child). In 15 the initial chest radiograph showed bilobar pneumonia; eight had pleural effusions. Repeat inpatient chest radiographs were taken in 18 children, of whom 10 were recovering uneventfully from uncomplicated lobar pneumonia. One showed resolution nine days after presentation, while the others showed resolving or unchanged appearances. Of eight children who had repeat inpatient films for poor progress or worsening clinical condition, four had developed effusions.

Fifty two children received intravenous drugs (usually co-amoxiclav) and 25 oral drugs (mostly erythromycin or co-amoxiclav). Sixty nine recovered uneventfully and eight showed slow clinical response or initial deterioration. There was no relation between antibiotic used or organism isolated and outcome.
Five of the 77 children defaulted from follow up. The table shows the results of chest radiography at initial follow up. Fifty one of 59 children with no symptoms or signs had complete radiological resolution. In the remaining eight, the clinicians reported seven chest radiographs as normal and one as showing clinically unimportant changes; radiologists reported four films as clear and four as showing minor changes; and ASH reported resolving minor changes in eight. Interobserver variation in reporting chest radiographs may account for this finding. ${ }^{3}$ Thus if clinical resolution had occurred no significant radiological abnormalities persisted at follow up.

Clinical and radiological findings at first follow up visit

\begin{tabular}{lrrcc}
\hline & & \multicolumn{3}{c}{ Radiological findings } \\
\cline { 3 - 5 } Clinical findings & $\begin{array}{c}\text { No of } \\
\text { children }\end{array}$ & Resolved & Improved & Unchanged \\
\hline Well-no symptoms or signs & 59 & 51 & 8 & \\
Symptoms but no signs & 11 & 4 & 6 & $1^{\star}$ \\
Signs & 2 & 1 & 1 & \\
\hline
\end{tabular}

${ }^{\star}$ Resolved at later review.

Of 13 children without complete clinical resolution at first follow up, five had radiological resolution. Seven of the eight with symptoms or signs and important findings on chest radiography at follow up had had effusions. All were followed up until complete resolution had occurred (maximum two further visits).

\section{Comment}

Radiological resolution of pneumonia is known to lag behind clinical resolution, ${ }^{4}$ but doctors repeat chest radiographs because of concern about missing persisting collapse or effusion. Our results suggested that in uncomplicated childhood pneumonia these concerns are unfounded and follow up radiographs are unnecessary. We also found repeat inpatient films were unhelpful if the child had improved clinically.

Our findings relate only to pneumonia in children. In adults a tumour partially obstructing a bronchus may become visible only after resolution of pneumonic changes and radiological follow up is therefore essential.

We conclude that, in the absence of pleural effusion, children with community acquired pneumonia who respond well to antibiotic treatment and are normal at follow up do not need further chest radiography.

1 Phelan PD, Landau LI, Olinsky A. Respiratory illness in children. London: Blackwell, 1990.

2 National Radiological Protection Board. Patient dose reduction in diagnostic radiology. Chilton, England: NRPB, 1990.

3 Kramer MS, Roberts-Brauer R, Williams RL. Bias and "overcall" in interpreting chest radiographs in young febrile children. Pediatrics 1992;90:11-3. 4 Singleton EB, Wagner ML, Dutton RV. Radiographic atlas of pulmonary abnormalities in children. Philadelphia: W B Saunders, 1988.

(Accepted 9 fuly 1993) 